\title{
Evaluation of Binding Confirmation Method for Ligand Binding to CD4 Receptor in HIV Infected T Lymphocytes.
}

\author{
P.B.Ramesh Babu, T.Jayalakshmi, R. Priya
}

\begin{abstract}
Pathogenic viruses has been reported to weaken the immune system by binding to CD4+ receptor of $T$ lymphocytes, thereby making the affected individual to become more susceptible to several microbial infections leading to life threatening problems. Recent literature indicate there is promsing advancement in identifying drug targets through CD4+ receptor binding capabilities with its ligand. The main purpose of this paper was to study the various molecular interactions of HIV to other molecules like receptors CD4+ and also co-receptors like CCR5 and CXCR4. The molecules are going to be modeled by using software known as Swiss PDB Viewer. The first objective is to get the FASTA sequence from the NCBI website. Then we need to paste the sequence onto the Swiss $P D B$ viewer. The requierd protein/molecule is modeled. We are going to follow this method to obtain templates and modles for the following molecukles: HIV, GP120, CCR5 and CXCR4.
\end{abstract}

Keywords : HIV infection, NCBI database, CD4,gp120 protein, Lymphocytes

\section{INTRODUCTION}

HIV prompts sickness because of the consumption of CD4+ T4 partner cells and the subsequent powerlessness to battle microbial infections. T4 cells are, of course, the significant cell type that is contaminated by the infection. Contaminated CD4+ T4 assistant cells progress toward becoming focuses for HIV-explicit CD8+ executioner cells yet beyond words an assortment of different causes. Amid the early intense disease arrange, for the most part mucosal CD4+ T4 cells are lost, while amid endless contamination that may last numerous years, CD4+ T4 cells by and large multiply beyond words a consequence of insusceptible enactment and different variables [26],[28],[30]

HIV infected cells that are noticeable in the patient in the ceaseless phase of disease are typically T4 memory cells while $\mathrm{T}$ cells display disease at a much lower recurrence. The HIV-tainted patient has a higher recurrence that typical of multiplying T4 cells because of general safe incitement and these cells are focuses for HIV (which just contaminates initiated CD4+ T cells). Along these lines, HIV prompts a consistent supply of its objective cells prompting further adjusts of replication and resistant obliteration $(3,4)$. The way

Revised Manuscript Received on July 22, 2019

P.B.Ramesh Babu Professor, Department of Genetics, Bharath Institute of Higher Education and Research (BIHER), Chennai -600073.

bioinfohodmail.com

G.Achuta Nursimhan Department of Genetics, Bharath Institute of Higher Education and Research (BIHER.

Dr. R. Priya Department of Genetics, Bharath Institute of Higher Education and Research (BIHER.

priya.microbio@gmai.com that HIV targets HIV-enacted T4 cells prompts the decrease of T4 cells that are explicit to HIV, in this manner exhausting the arm of the insusceptible framework that controls replication of the infection.

As noted somewhere else after enactment by a particular antigen, T4 cells either bite the dust or move toward becoming non-multiplying memory cells which are quickly assembled if the antigen is in this way reencountered. This inactive repository of contaminated T4 cells can get by for a long time, even within the sight of the present enemy of HIV drugs (HAART - profoundly dynamic enemy of retroviral treatment) that seem to smother HIV replication totally. This is on the grounds that when a contaminated T4 cell returns to the resting, memory, state it never again duplicates infection (that is makes the viral proteins and genomic RNA) yet the cell still harbors a DNA duplicate of HIV (the provirus) incorporated into its chromosomes. On reactivation of the cells by antigen, viral replication resumes. [19],[21],[23]

In this paper, after getting the models then we will dock the molecukles by using bioinformatics tools. In docking we will test to see the various molecules interacting with each other. We want to dock HIV and GP120 (Fig 1) and save it as a complex and then dock the two chemokine receptors and save it as a complex and then try to dock the two complexes with one another. HIV lyses CD4+ T4 cells explicitly, causing significant immuno-concealment. Different cells will in general harbor and reproduce the infection without lysis or, on account of dendritic cells, they may assemble infection at the cell surface with next to zero replication of the infection.

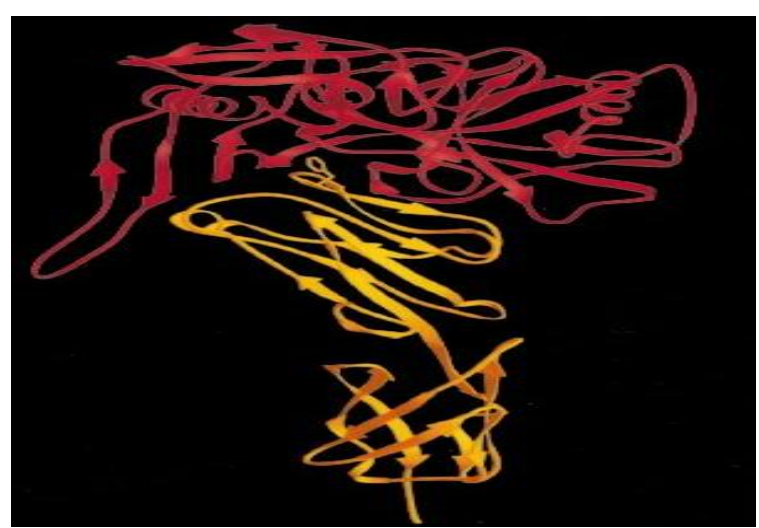

Figure 1. Ribbon diagram of HIV gp120 in complex with CD4.

The gp120 is shown in red; CD4 is shown in yellow. The structure of gp120 has "no point of reference," as indicated by the individuals who concluded its structure (5-7)). The inward area contains no homologous groupings to some other

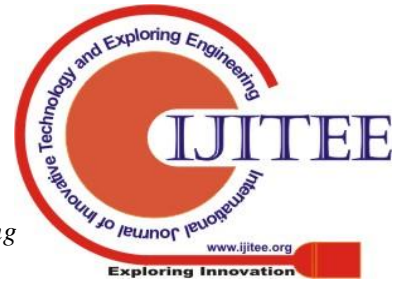


living being, while there is some sporadic homology among areas of the external space. One external segment bears homology to a dehydrase advertiser, while another segment has some arrangement homology to a dUTP pyrophosphatase. dUTP pyrophosphatase is a catalyst found in infections identified with HIV, despite the fact that there is no proof yet that connects this chemical to the protein coat $(8-11)$. The protein itself demonstrates wide inconstancy in arrangement among strains of the infection, yet there are a few successions that demonstrate some protection. When all is said in done, the inward area is significantly more rationed than the external space, probably demonstrating some basic capacity. The glycosylation locales themselves are likewise exceptionally preserved [31],[33],[35]

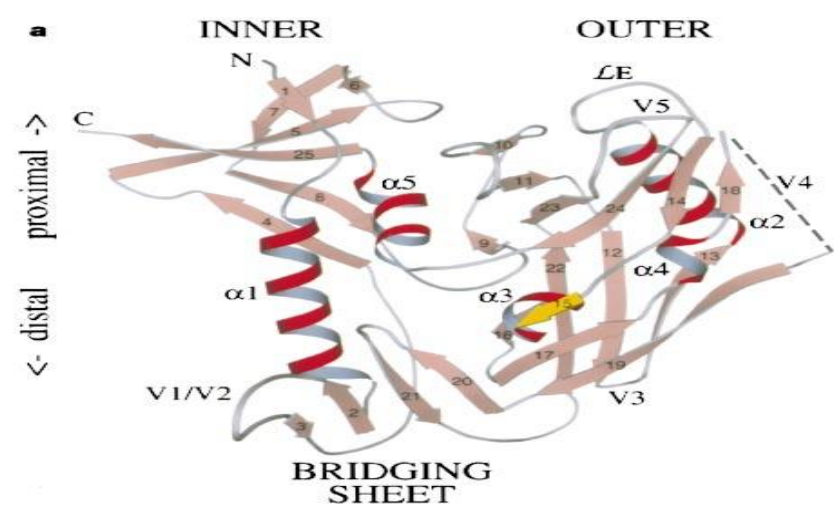

Figure 2. Structure of gp120. In connection to past figure, this structure has been turned 180 degrees. Note the nearness of external and internal areas, and the cavity situated between them. The CD4/gp120 restricting site is inside this depression. [25],[27],[29]

In a finding that opens new ways to conceiving medications and antibodies against HIV, researchers have solidified the center of gp120 (Fig 2), the surface protein particle that the infection uses to join itself to safe framework cells. The new model of the gp120 center's precious stone structure uncovers explicit focuses for hostile to HIV antibodies and medications, and features the amazing exhibit of safeguards that the infection uses to sidestep assault. "Concentrate the gp120 precious stone's structure can disclose to us much increasingly about how the infection bolts on to resistant framework cells," says Anthony S. Fauci, M.D., chief of the National Institute of Allergy and Infectious Diseases (NIAID). "We currently have explicit target locales on which to center in growing new medications and immunizations." [13], [15], [17]

\section{A.Strategies:-}

Impact (Basic Local Alignment Search Tool) is an utility that is kept up by the National Center for Biotechnology Information (NCBI). A BLAST seek empowers an analyst to contrast a question succession and a library or database of groupings, and distinguish library arrangements that look like the inquiry succession over a specific edge... The BLAST wrapper underpins every one of the five sorts of BLAST seeks: BLASTn, BLASTp, BLASTx, tBLASTn, and tBLASTx. These are portrayed beneath. Impact requires an inquiry grouping to scan for, and a succession to seek against (additionally called the objective arrangement) or an arrangement database containing different such successions. Impact will discover subsequences in the database which are like subsequences in the inquiry. In commonplace utilization, the question grouping is a lot littler than the database, e.g., the inquiry might be one thousand nucleotides while the database is a few billion nucleotides. [37],[39],[41]

FASTA is a DNA and protein grouping arrangement programming bundle initially depicted (as FASTP) by David J. Lipmann and William R. Pearson in 1985 in the article Rapid and delicate protein likeness seeks. The first FASTP program was intended for protein arrangement likeness seeking. FASTA, depicted in 1988 (Improved Tools for Biological Sequence Comparison) added the capacity to do DNA: DNA looks, deciphered protein: DNA seeks, and furthermore gave an increasingly complex rearranging program for assessing measurable criticalness. There are a few projects in this bundle permit the arrangement of protein groupings and DNA successions. FASTA is articulated "Quick Aye", and means "Quick All", since it works with any letter set, an expansion of "Quick P" (protein) and "Quick N" (nucleotide) arrangement. [32],[34],[36]

In database pursuits, for example, BLAST, factual techniques can decide the probability of a specific arrangement between groupings or succession areas emerging by chance given the size and organization of the database being looked. These qualities can change fundamentally relying upon the pursuit space. Specifically, the probability of finding a given arrangement by chance increments if the database comprises just of groupings from indistinguishable creature from the MS-4, MS-21, MS-22query succession. Monotonous arrangements in the database or question can likewise mutilate both the indexed lists and the evaluation of factual importance; BLAST consequently channels such tedious groupings in the inquiry to stay away from obvious hits that are measurable curios.

Homology displaying can create high caliber basic models when the objective and layout are firmly related, which has roused the development of an auxiliary genomics consortium committed to the generation of agent trial structures for all classes of protein folds. The central mistakes in homology demonstrating, which compound with lower grouping personality, get from blunders in the underlying succession arrangement and from inappropriate layout determination. Like different strategies for structure forecast, current practice in homology demonstrating is surveyed in a semiannual huge scale explore known as the Critical Assessment of Techniques for Protein Structure Prediction, or CASP. [8],[ 10] ,[12]

A general worldview of protein threading comprises of the accompanying four stages: The development of a structure format database Select protein structures from the protein structure databases as auxiliary layouts. This for the most part includes choosing protein structures from databases, for example, PDB, FSSP, SCOP, or CATH, in the wake of expelling protein structures with high arrangement similitudes. The plan of the scoring capacity to gauge the wellness between target 
arrangements and formats dependent on the information of the known connections between the structures and the groupings. A decent scoring capacity ought to contain change potential, condition wellness potential, pairwise potential, auxiliary structure compatibilities, and hole punishments. The nature of the vitality work is firmly identified with the forecast precision, particularly the arrangement exactness.

Threading arrangement:- Align the objective grouping with every one of the structure layouts by streamlining the planned scoring capacity. This progression is one of the real undertakings of all threading-based structure expectation programs that consider the pair shrewd contact potential; generally, a dynamic programming calculation can satisfy it. This proposal is for the most part devoted to tackling the ideal arrangement issue got from a scoring capacity considering pair shrewd contacts. Threading expectation:- Select the threading arrangement that is measurably most plausible as the threading forecast. At that point develop a structure demonstrate for the objective by putting the spine molecules of the objective succession at their adjusted spine places of the chose basic format. [14], [16], [18]

\section{Stomach muscle initio protein demonstrating:-}

Stomach muscle initio-or again protein demonstrating strategies try to assemble three-dimensional protein models "starting with no outside help", i.e., in view of physical standards instead of (specifically) on recently understood structures. There are numerous conceivable systems that either endeavor to emulate protein collapsing or apply some stochastic technique to seek conceivable arrangements (i.e., worldwide improvement of a reasonable vitality work). These methodology will in general require huge computational assets, and have in this way just been completed for small proteins. To foresee protein structure all over again for bigger proteins will require better calculations and bigger computational assets like those managed by either ground-breaking supercomputers, (for example, Blue Gene or MDGRAPE-3) or circulated figuring, (for example, Folding@home, the Human Proteome Folding Project and Rosetta@Home). In spite of the fact that these computational boundaries are huge, the potential advantages of auxiliary genomics (by anticipated or test strategies) make abdominal muscle initio structure forecast a functioning examination.

\section{II.RESULTS AND DISCUSSION}

Homology demonstrating and protein threading are both layout based strategies and there is no thorough limit between homology displaying and protein threading as far as forecast systems. Be that as it may, the protein structures they focus at are unique. Homology demonstrating is for those objectives that have homologous proteins with known structure. As referenced, protein threading is for those objectives with just overlap level homology found. As it were, homology displaying is for obvious objectives and protein threading is for hard targets.

Homology displaying treats the layout in an arrangement as a grouping and just succession homology is utilized for forecast. Protein threading treats the format in an arrangement as a structure and both grouping and structure data extricated from the arrangement are utilized for expectation (Figure 3). At the point when there is no huge homology discovered, protein threading can make an expectation dependent on the structure data. That additionally clarifies why protein threading might be more powerful than homology displaying much of the time. By and by, when the succession personality in an arrangement grouping arrangement is low (for example <25\%), homology demonstrating may not create a huge forecast. For this situation, if there is inaccessible homology found for the objective, protein threading can create a decent forecast. Forecast of three dimensional structure of an objective protein from the amino corrosive succession (essential structure) of a homologous (layout) protein for which a $\mathrm{X}$-beam or NMR structure is accessible.

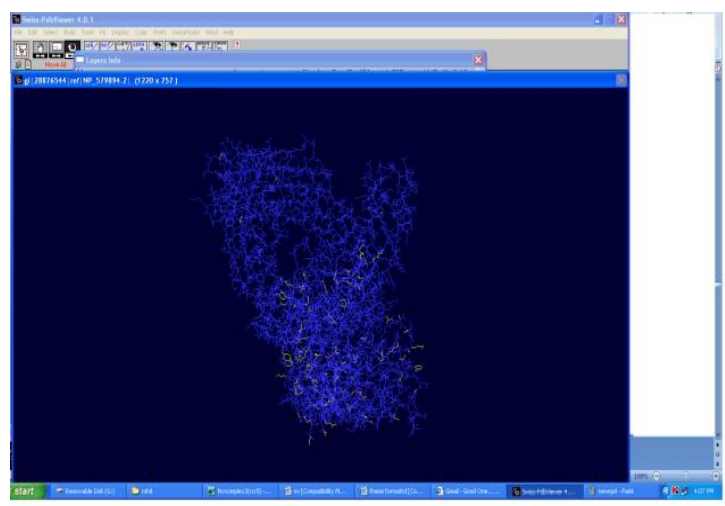

Figure 3 : The result of the model displayed using the spdb viewer

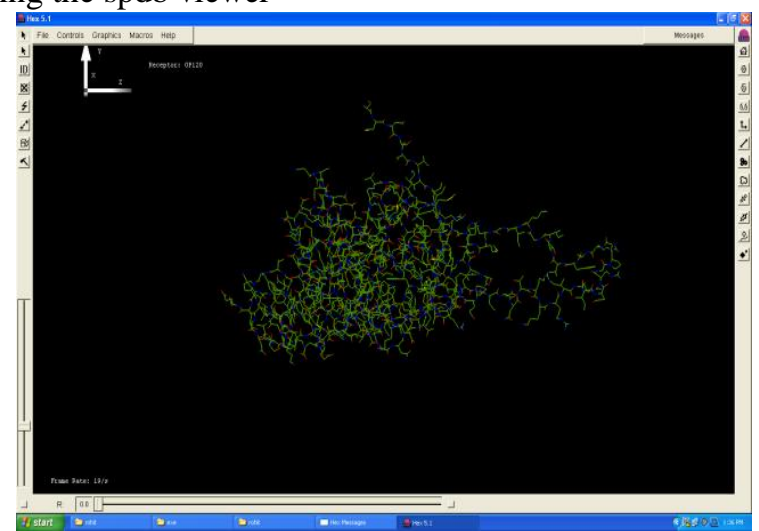

Figure 4: Result of the required molecule. Hex homepage for docking

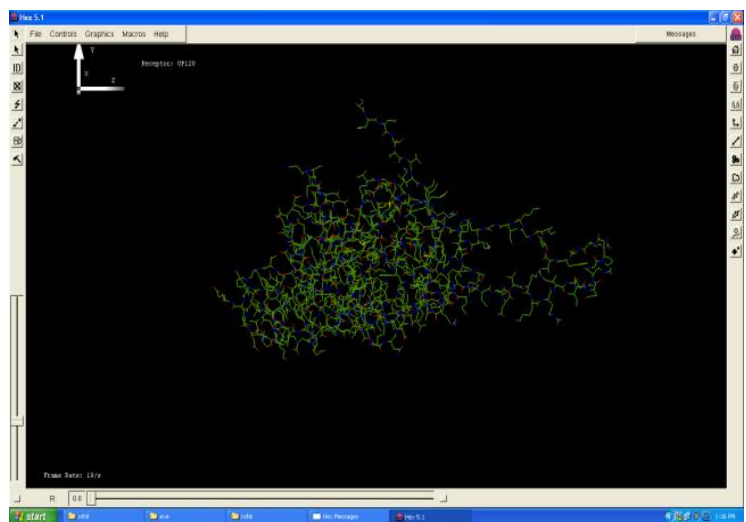

Figure 5: Select the gp120 receptor pdb format file.

Published By: 
According to the protein structure expectation techniques like Homology Modeling, Threading and $\mathrm{Ab}$ initio strategies, we should discover the layout for our succession of intrigue (Figure 4 and 5). While finding the format we have searched for the $\%$ personality or closeness between the grouping of intrigue and layout. According to the demonstrating situation, if the $\%$ personality is over $60 \%$, we ought to go for Homology displaying, if is in the scope of $25-60 \%$; ought to go for threading strategy and on the off chance that it is beneath 20-25\%; ought to go for Ab Initio technique. According to the $\%$ character we have from format in the wake of sending layout choice demand either through Swiss PDB watcher or specifically through the online Swiss model server, we have picked the homology displaying technique for structure forecast. Modeling for the Sequences of interest has done by Swiss PDB Viewer offline tool or by directly the automated mode for structure prediction available online on Swiss-Model Server. It has given us with the final predicted structure based on the template structure so as to predict the function of the sequence of interest. Here we have got the structures of HIV1 gp120 on the basis of template 2B4C. And Human CD4+ structure on the basis of the template.

In docking, we are supposed to manipulate the receptor and ligand molecules before we will be going for docking. Manipulations are to be done according to the Tool which we are going to use for docking purpose. Here we have used Hex docking platform which has manipulating criteria in terms of enabling solvent, enabling hetero and enabling Arg/Lysine. This has to be done by the enabling all this options so as to create the live environment for docking as that of in vivo process of ligand and receptor binding. When we have started with the docking, first thing we considered is Estart and then simultaneously Emin and Emax. These values are to be considered energy should be minimized so as to make the molecule stable as, more the rotatable bonds in ligand, the more difficult it will be to find good binding modes in repeated docking experiments. Thus final result that is the Etotal should lie in between Emin and Emax. Etotal should be always less so as to get the maximum stability to docking complex for perfect merge and also less than Estart.

The scoring capacity accepts a posture as information and returns a number demonstrating the probability that the posture speaks to a positive restricting cooperation. Most scoring capacities are material science based sub-atomic mechanics drive handle that gauge the vitality of the represent; a low (negative) vitality demonstrates a steady framework and therefore a reasonable restricting association. An elective methodology is to determine a factual potential for collaborations from a substantial database of protein-ligand buildings, for example, the Protein Data Bank, and assess the attack of the posture as per this deduced potential.

CD4 (bunch of separation 4) is a glycoprotein communicated on the outside of $\mathrm{T}$ partner cells, administrative $\mathrm{T}$ cells, monocytes, macrophages, and dendritic cells. It was found in the late 1970s and was initially known as leu-3 and T4 (after the OKT4 monoclonal counter

acting agent that responded with it) before being named CD4 in 1984. In people, the CD4 protein is encoded by the CD4 quality. In the homology demonstrating structure expectation technique, we have anticipated the structure of HIV1 gp120 and Human CD4+. \% character demonstrates the comparability in capacities. According to the $\%$ character we got which is over $60 \%$, we made with the end that our succession of intrigue has identical capacity as that of the format. That implies, (clarify the capacity of cd4+ n hiv1gp120).

According to the discourses, the ETotal for the HIV gp120 and human CD4+should be not exactly Estart and should lie in the middle of Emin and Emax. According to the docking results we got EStart was $47.50 \mathrm{KJ} / \mathrm{mol}$ and our Etotal is-244.0 KJ/mol. So it is not exactly Estart and it's additionally lying towards Emin. So we are getting steady unpredictable according to the docking result. So this docking complex is substantial one complex and these two atoms gp120 and cd4+ are having restricting fondness which really implied for the HIV disease..

\section{REFERENCES}

1) Sharmila S., Jeyanthi Rebecca L., Das M.P.,Production of Biodiesel from Chaetomorpha antennina and Gracilaria corticata,Journal of Chemical and Pharmaceutical Research,V-4,I-11,PP-4870-4874,Y-2012

2) Aarthi C., Ramesh Babu P.B.,Anti-cancer activity of Phyllanthus reticulatus on colon cancer cell line, International Journal of Civil Engineering and Technology,V-8,I-1,PP-943-947,Y-2017

3) Sharmila S., Jeyanthi Rebecca L., Das M.P., Saduzzaman M.,Isolation and partial purification of protease from plant leaves,Journal of Chemical and

Research,V-4,I-8,PP-3808-3812,Y-2012

4) Jayalakshmi T., Krishnamoorthy P., Ramesh Babu P.B., Vidhya B.,Production, purification and Biochemical characterization of alkaline Fibrinolytic enzyme from Bacillus subtilisstrain-GBRC1,Journal of Chemical and Pharmaceutical Research,V-4,I-12,PP-5027-5031,Y-2012

5) Jeyanthi Rebecca L., Susithra G., Sharmila S., Das M.P.,Isolation and screening of chitinase producing Serratia marcescens from soil,Journal of Chemical and Pharmaceutical Research,V-5,I-2,PP-192-195,Y-2013

6) Aarthi C., Ramesh Babu P.B.,Antimicrobial and antioxidant activity of phyllanthus niruri,International Journal of Pharmacy and Technology,V-8,I-2,PP-14701-14707,Y-2016

7) Anbuselvi S., Jeyanthi Rebecca L., Sathish Kumar M., Senthilvelan T.,GC-MS study of phytochemicals in black gram using two different organic manures,Journal of Chemical and Pharmaceutical Research,V-4,I-2,PP-1246-1250,Y-2012

8) Soniyapriyadharishni A.K., Ramesh Babu P.B.,Data mining strategies for identification of HNF4A MODY gene using gene prioritize tool,Journal of Chemical and Pharmaceutical Research,V-6,I-3,PP-1126-1133,Y-2014

9) Sharmila S., Jeyanthi Rebecca L., Naveen Chandran P., Kowsalya E., Dutta H., Ray S., Kripanand N.R.,Extraction of biofuel from seaweed and analyse its engine performance,International Journal of Pharmacy and Technology,V-7,I-2,PP-8870-8875,Y-2015

10) Sharmila S., Jeyanthi Rebecca L., Saduzzaman M.,Biodegradation of domestic effluent using different solvent extracts of Murraya koenigii,Journal of Chemical and Pharmaceutical Research,V-5,I-2,PP-279-282,Y-2013

11) Jeyanthi Rebecca L., Sharmila S., Das M.P., Seshiah C.,Extraction and purification of carotenoids from vegetables,Journal of Chemical and Pharmaceutical Research,V-6,I-4,PP-594-598,Y-2014

12) Krishnamoorthy P., Praveen Kumar P.K., Ramesh Babu P.B.,Community based evaluation based
of 
phenylthiocarbamide (PTC) sensitivity and Dermatoglyphics as a genetic marker in Tamilnadu, India,International Journal of Pharmacy and Technology,V-5,I-3,PP-5705-5712,Y-2013

13) Sharmila S., Jeyanthi Rebecca L.,GC-MS Analysis of esters of fatty acid present in biodiesel produced from Cladophora vagabunda,Journal of Chemical and Pharmaceutical Research,V-4,I-11,PP-4883-4887,Y-2012

14) Sinha S., Rajasulochana P., Ramesh Babu P.B., Krishnamoorthy P.,Comparative modelling of shikimate kinase $(\mathrm{M} \mathrm{Tb})$ and molecular docking studies of its known inhibitors, Research Journal of Pharmaceutical, Biological and Chemical Sciences, V-4,I-3,PP-715-720,Y-2013

15) Jeyanthi Rebecca L., Dhanalakshmi V., Sharmila S.,Effect of the extract of Ulva sp on pathogenic microorganisms,Journal of Chemical and Pharmaceutical Research,V-4,I-11,PP-4875-4878,Y-2012

16) Sharmila S., Jeyanthi Rebecca J.,A comparative study on the degradation of leather industry effluent by Marine algae,International Journal of Pharmaceutical Sciences Review and Research,V-25,I-2,PP-46-50,Y-2014

17) Ramesh Babu P.B., Krishnamoorthy P., Gayathri G.,Identification of drug target site on citrate synthase of food pathogen - Campylobacter jejuni,Research Journal of Pharmaceutical, Biological and Chemical Sciences,V-4,I-1,PP-618-623,Y-2013

18) Sharmila S., Rebecca Jeyanthi L., Saduzzaman M.,Biodegradation of tannery effluent using Prosopis juliflora,International Journal of ChemTech Research,V-5,I-5,PP-2186-2192,Y-2013

19) Kumar S., Das M.P., Jeyanthi Rebecca L., Sharmila S.,Isolation and identification of LDPE degrading fungi from municipal solid waste,Journal of Chemical and Pharmaceutical Research,V-5,I-3,PP-78-81,Y-2013

20) Das M.P., Jeyanthi Rebecca L., Sharmila S., Anu, Banerjee A., Kumar D.,Identification and optimization of cultural conditions for chitinase production by Bacillus amyloliquefaciens SM3,Journal of Chemical and Pharmaceutical Research,V-4,I-11,PP-4816-4821,Y-2012

21) Ramesh Babu P.B., Krishnamoorthy P., Rekha R.,Develoment of comprehensive online database model for genes responsible for asthma,Research Journal of Pharmaceutical, Biological and Chemical Sciences, V-4,I-1,PP-865-871,Y-2013

22) Devi M., Jeyanthi Rebecca L., Sumathy S.,Bactericidal activity of the lactic acid bacteria Lactobacillus delbreukii,Journal of Chemical and Pharmaceutical Research,V-5,I-2,PP-176-180,Y-2013

23) Ramesh Babu P.B., Miller T.L., Chidekel A., Shaffer T.H.,Clara cell protein mediates secretion of proteins, IL-8 and IL-6 in human airway epithelial cell line Calu-3 exposed to hyperoxia,Journal of Chemical and Pharmaceutical Research,V-4,I-6,PP-3164-3170,Y-2012

24) Bhuvaneswari B., Hari R., Vasuki R., Suguna,Antioxidant and antihepatotoxic activities of ethanolic extract of Solanum torvum,Asian Journal of Pharmaceutical and Clinical Research,V-5,I-SUPPL. 3,PP-147-150,Y-2012

25) Abraham Samuel F., Mohan V., Jeyanthi Rebecca L.,Physicochemical and heavy metal analysis of sugar mill effluent,Journal of Chemical and Pharmaceutical Research,V-6,I-4,PP-585-587,Y-2014

26) Narayani P.C., Anbu J., Vasuki R., Hari R.,Invitro and invivo anti-arthritic activity of combined ethanolic extracts of Calotropis gigantea and Cardiospermum halicacabum in Wistar rats,Journal of Natural Remedies, V-14,I-1,PP-58-66,Y-2014

27) Paul Das M., Jeyanthi Rebecca L., Sharmila S., Anu, Banerjee A., Kumar D.,Identification and optimization of cultural conditions for chitinase production by Bacillus amyloliquefaciens SM3,Journal of Chemical and Pharmaceutical Research,V-4,I-12,PP-4969-4974,Y-2012

28) Vasuki R., Hari R., Pandian S., Arumugam G.,Hepatoprotective action of ethanolic extracts of eclipta alba and piper longum linn and their combination on CCL 4 induced hepatotoxicity in rats,International Journal of Pharmacy and Pharmaceutical Sciences, V-4,I-SUPPL.1,PP-455-459,Y-2012

29) Saduzaman M., Sharmila S., Jeyanthi Rebecca L.,Efficacy of leaf extract of Moringa oleifera in treating domestic effluent,Journal of Chemical and Pharmaceutical Research,V-5,I-2,PP-139-143,Y-2013

30) Senthil Kumar K., Vasuki R., Priya R.,Green synthesis, pegylation of silver nano herbal complexand study of its anti-mutagenicity activity,International Journal of Pharmacy and Technology,V-8,I-2,PP-12130-12143,Y-2016
31) Srivastava S., Seethalakshmi I., Jeyanthi Rebecca L.,Antimicrobial and antioxidant properties of cissus quandrangularis,Journal of Chemical and Pharmaceutical Research,V-5,I-5,PP-131-134,Y-2013

32) Gireeshan M.G., Vasuki R., Krishnakumar T.,High power production from elephantâ $€^{\mathrm{TM}_{\mathrm{S}}}$ urine,International Journal of Pharmacy and Technology,V-6,I-2,PP-6714-6718,Y-2014

33) Jeyanthi Rebecca L., Dhanalakshmi V., Sharmila S., Das M.P.,In vitro antimicrobial activity of Gracilaria SP and Enteromorpha SP,Research Journal of Pharmaceutical, Biological and Chemical Sciences, V-4,I-1,PP-693-697,Y-2013

34) Jeyanthi Rebecca L., Dhanalakshmi V., Thomas T.,A comparison between the effects of three algal extracts against pathogenic bacteria,Journal of Chemical and Pharmaceutical Research,V-4,I-11,PP-4859-4863,Y-2012

35) MohdHelmyAbdWahab, Amirul A. Talib, Herdawatie A. Kadir, Ayob Johari, A.Noraziah, Roslina M. Sidek, Ariffin A. "Smart cane: assistive cane for visually impairedpeople", IJCSI, Vol.8 Issue 4, July 2011

36) M. Bousbia-Salah, A. Larbi, and M. Bedda, "An approach for the measurement of distance travelled by blind and visually impaired people," in Proc. 10th IEEE Inter

37) Brabyn, J. A. (1985). A review of mobility aids and means of assessment. In D. H.Warren\&amp; E. R. Strelow (Eds.), Electronic Spatial Sensing For the Blind-ContributionsFrom Perception, Rehabilitation, and Computer Vision (pp. 13- 27). Boston, MA: MartinusNijhoff Publishers

38) Heyes, "A polaroid ultrasonic travel aid for the blind," Journal of Visual Impairment and Blindness, vol. 76, pp. 199-201, 1982.

39) ShrutiDambhare M.E 3rd SEM (ESC) G.H.R.C.E. Nagpur, Prof. A SakhareM.Tech(ESC) G.H.R.C.E. Nagpur Smart stick for Blind: Obstacle Detection, Artificial vision and Real- time assistance via GPS.

40) Michel Mouly and Marie-Bernadette Pautet: GSM System for Mobile Communicationspublished by the authors 1992, ISBN 2-95071900-7 [4] Majid Al Shamsi, Mahmoud Al- Qutayri, and Jeedella, "Blind Assistant Navigation System" in IEEE Transactions, March 2011.

41) A. R. Garcia, R. Fonseca. A. Duran. \&quot;Electronic long cane for locomotion improving on visual impaired people.\&quot; IEEE, pp.58-61, 2011

42) G.Gayathri,M.Vishnupriya,R.Nandhini, Ms.M.Banupriya "SMART WALKING STICK FOR VISUALLY IMPAIRED" International JournalOf Engineering And ComputerScience ISSN:2319-7242 Volume 3 Issue 3 March, 2014 Page No. 4057-4061.

43) ArijitDatta "Advanced GPS \&amp; GSM Based Navigation System for Blinds" International Journal for Research in Technological Studies Vol. 1, Issue 6, May 2014 | ISSN (online):2348-1439.

44) Amit Kumar, Rusha Patra, M. Manjunatha, J. Mukhopadhyay and A K. Majumdar an electronic travel aid for navigation of visually impaired Communication Systems andNetworks (COMSNETS), 2011 Third International conference on 4-8 jan 2011.

45) Shamsi, M.A.; Al-Qutayri, M.; Jeedella, J.; Blind assistant navigation systemBiomedical Engineering (MECBME), 2011 1st Middle East Conference on 2124 Feb. 2011

46) Michel Mouly and Marie-Bernadette Pautet: GSM System for Mobile Communications, published by the authors 1992, ISBN 2-95071900-7 [4] Majid AlShamsi,Mahmoud Al-Qutayri, and Jeedella, "Blind Assistant Navigation System” in IEEETransactions, March 2011. 


\section{AUTHORS PROFILE}

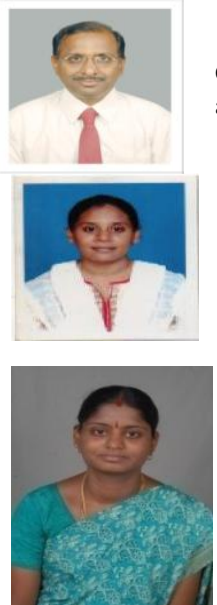

P.B.Ramesh Babu Professor, Department of Genetics, Bharath Institute of Higher Education and Research (BIHER), Chennai -600073.

Dr. R. Priya Department of Genetics, Bharath Institute of Higher Education and Research (BIHER.

Jayalakshmi, Professor, Department of

Genetics, Bharath Institute of Higher

Education and Research (BIHER), Chennai

-600073 .. 